\title{
Location Optimization of a Coal Power Plant to Balance Costs against Plant's Emission Exposure
}

\author{
Najam Khan ${ }^{*}$, Ekaterina Koromyslova² \\ ${ }^{1}$ Department of Project Management and Operations Research, CSW, Olympia, WA, USA \\ ${ }^{2}$ Department of Construction and Operations Management, South Dakota State University, Brookings, SD, USA \\ Email: *najam.khan@jacks.sdstate.edu
}

How to cite this paper: Khan, N. and Koromyslova, E. (2019) Location Optimization of a Coal Power Plant to Balance Costs against Plant's Emission Exposure. American Journal of Operations Research, 9, 31-58.

https://doi.org/10.4236/ajor.2019.91003

Received: November 6, 2018

Accepted: January 28, 2019

Published: January 31, 2019

Copyright $\odot 2019$ by author(s) and Scientific Research Publishing Inc. This work is licensed under the Creative Commons Attribution-NonCommercial International License (CC BY-NC 4.0).

http://creativecommons.org/licenses/by-nc/4.0/

\begin{abstract}
The goal of the research is to develop a methodology to minimize the public's exposure to harmful emissions from coal power plants while maintaining minimal operational costs related to electric distribution losses and coal logistics. The objective is achieved by combining EPA Screen3, ISC3 and Japanese METI-LIS model equations with minimum spanning tree (MST) algorithm. Prim's MST algorithm is used to simulate an electric distribution system and coal transportation pathways. The model can detect emission interaction with another source and estimate the ground level concentrations of emissions up to distances of 25 kilometers. During a grid search, the algorithm helps determine a candidate location, for a new coal power plant, that would minimize the operational cost while ensuring emission exposure is below the EPA/NIOSH thresholds. The proposed methodology has been coded in form of a location analysis simulation. An exhaustive search strategy delivers a final candidate location for a new coal power plant to ensure minimum operational costs as compared to the random or greedy search strategy. The simulation provides a tool to industrial zone planners, environmental engineers, and stakeholders in coal-based power generation. Using operational and emissions perspectives, the tool helps ascertain a list of compromise locations for a new coal power plant facility.
\end{abstract}

\section{Keywords}

MCDA-Operations Research, Location Analysis, Prim's Algorithm, Atmospheric Pollution Modelling, Transportation Cost

\section{Introduction}

In 2017, the United States' primary source of energy for power generation was 
fossil fuels. Coal accounted for $30.1 \%$ of the total share followed by $31.7 \%$ for natural gas and $0.9 \%$ for liquid fuels [1]. World electric power consumption in 2015 stood at 23.5 trillion $\mathrm{kWh}$ with expected growth to 34 trillion kWh by 2040 . Currently, the worldwide coal usage per annum for electric power generation stands at 3.34 billion tons. Figure 1 shows worldwide coal consumption projections from various regions [2].

Coal upon combustion produces $\mathrm{CO}_{2}, \mathrm{SO}_{2}, \mathrm{NO}_{\mathrm{x}}, \mathrm{CO}$, Metallic and Particle Matter $\left(\mathrm{PM}_{10} \& \mathrm{PM}_{2.5}\right)$. The presence of these chemical compounds in the atmosphere in close vicinity to humans, livestock, and agriculture carries detrimental health consequences.

Fuel and its delivery cost comprise the biggest expense in coal power plant operations. Delivery of electricity from generation to consumers requires investment in power lines and transmission grids. For example, a $69 \mathrm{kV}$ overhead single transmission line costs about $\$ 285,000$ per mile while a $138 \mathrm{kV}$ overhead transmission line costs about $\$ 390,000$ per mile [3].

Placing a coal power plant or multiple power plants near dense population centers can lower transmission costs. If a coalmine is nearby, transportation costs can also be reduced. However, emissions from coal plants have played a key role in worsening health crises in many countries, like India and China [4] [5]. For example, a stoker fired boiler burning one ton of anthracite coal emits $17.67 \mathrm{~kg}$ of $\mathrm{SO}_{\mathrm{x}}, 4.08 \mathrm{~kg}$ of $\mathrm{NO}_{\mathrm{x}}, 0.272 \mathrm{~kg}$ of $\mathrm{CO}, 2574 \mathrm{~kg}$ of $\mathrm{CO}_{2}, 0.004 \mathrm{~kg}$ of $\mathrm{Pb}$, and $0.136 \mathrm{~kg}$ of toxic organic compounds (TOC) etc. [6].

In the last two decades, awareness has risen regarding air pollution and increasing global temperature due to increased carbon dioxide emission and ozone depletion because of chlorofluorocarbon (CFC) activity. With $40.665 \%$ of world electric energy demand being met by coal power plants [7], it is imperative that new coal power spatial placement must be done not only from an economical point of view but also from an environmental point of view. There is a need to balance coal power plant location decision based on transmission and operational costs with the environmental impact on the local population; keeping profits and environmental consequences balanced.

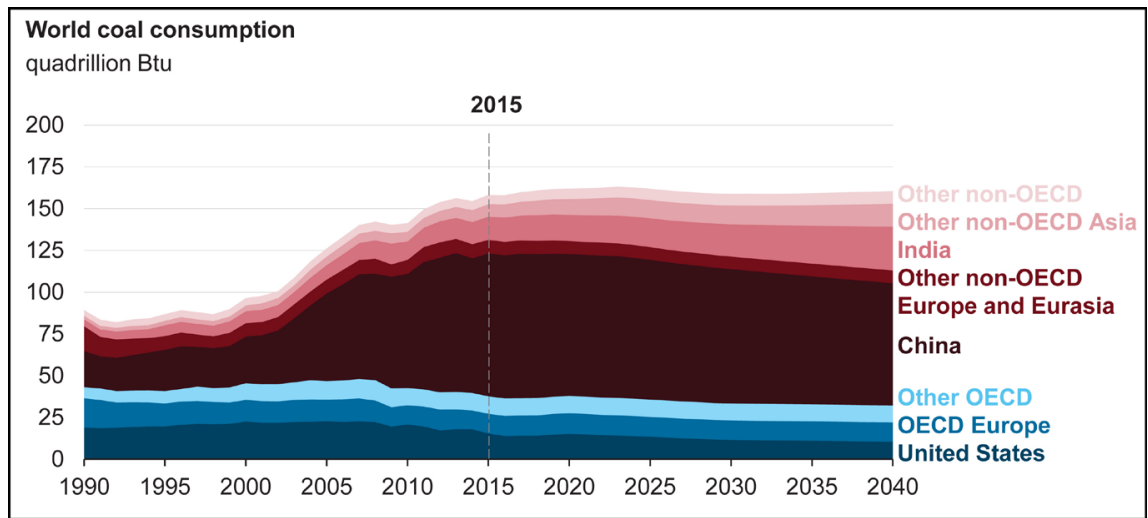

Figure 1. World coal consumption 2015-2040 [2]. 
The problem of study is to develop an approach that uses current location decision techniques and strategies of optimization coupled with financial and emission dispersion models. Additionally, to use the approach to calculate an optimal location for a new power plant in a certain geographical area. The goal is to minimize the cost of electric transmission and emission interaction with other point source emissions.

The purpose of this study is to develop a dynamic program that allows city planners, industrial zone managers, coal power plant owners, and supply chain managers to determine the best compromized location for a coal power plant. The program goal is to assure both minimal total cost (production and transmission costs) and environmental impact.

The following research questions are formulated for the study:

1) Which plume dispersion model can be combined with the location optimization algorithm in the proposed dynamic program that results in a compromized plant location, where National Ambient Air Quality Standards (NAAQS) pollutant criteria are met and operational cost criteria minimized?

2) Does the developed methodology assure better location for a coal power plant where the cost of coal logistics as well as electric transmission is less, compared to a random pick or a greedy decision?

3) Does the power plant emission foot print for the determined location keeps the pollution factor less than the National Ambient Air Quality Standards (NAAQS) threshold for $95 \%$ of the location population?

The following assumptions are made for the research:

1) Coal power plant emissions are continuous and follow a Gaussian dispersion model with steady state weather conditions.

2) Power plant coal consumption relates directly to the amount of power requirement. Line losses are non-linear depending on load covered by distance on each edge of the transmission network.

3) The pollutants from exhaust do not undergo any chemical transformation upon interaction with the environment.

4) Target consumers and coalmine positions on the map remain static.

Limitations of the study are as follows:

1) Currently the range of emission modeling is for a $100 \mathrm{~km} \times 100 \mathrm{~km}$ grid.

2) Building downwash has not been considered.

3) Assumption of a constant 90-degree east wind direction on all models.

4) The model does not take into consideration deviation in plume dispersion due to any urban growth caused by installation of a new power plant.

In the next section, a detailed literature review focuses on the background of various atmospheric dispersion models, health risks posed by various pollutants, the cost of coal transport, electric transmission losses, and location analysis strategies.

\section{Literature Review}

In the $21^{\text {st }}$ century, the issue of environmental awareness has been on the rise. 
Various studies and methodologies have been published which attempted to quantify the distribution of emissions from various industries over a geographical area.

\subsection{Atmospheric Dispersion Models}

The Environmental Protection Agency (EPA), as a part of their mission to protect human health and environment, has made significant contributions in development of various atmospheric models. These models take inputs like meteorological conditions, emission rates, and stack heights to simulate emitted matter's dispersion and chemical reactions in the atmosphere. Regulation agencies use these models in permitting processes, determining additional control requirements, predicting future concentrations in atmosphere from multiple resources and characterization of primary and secondary pollutants [8].

The EPA has recommended AERMOD and CALPUFF modeling systems for state implementation plans, new source review, and prevention of significant deterioration programs. AEROMOD is a steady state plume modeler that measures pollutant dispersion, based upon characteristics of the surface boundary layer, the convective boundary layer and the planetary boundary layer, coupled with terrain characteristics and meteorological conditions. CALPUFF is a non-steady state model that measures pollutant dispersion and transformation over long-range distances under ever changing spatial and time varying meteorological conditions as well as complex terrain. Other recommended models published are BLP, CALINE3, CAL3QHC/CAL3QHCR, CTDMPLUS, and OCD [8]. BLP is based upon a Gaussian plume dispersion model associated with modeling industrial sources where plume rise and downwash effects are important from point sources. CALINE3 is a steady state Gaussian plume dispersion model for air pollution dispersion at receptor locations. CTDMPLUS is a Gaussian air quality model for stable meteorological conditions and complex terrain. A group of alternative models are also presented by the EPA and can be applied on a case by case basis with proper reasoning. These include ADAM, ADMS-3, AFTOX, ASPEN, DEGADIS, HGSYSTEM, HOTMAC/RAPTAD, HYROAD, ISC3, ISC-Prime, OBODM, OZIPR, Panache, PLUVUEII, SCIPUFF, SDM, and SLAB.

Kaw Nation Environmental Agency in Kaw City, Oklahoma, used the AEROMOD modeler to estimate the concentration of $\mathrm{SO}_{2}$ and $\mathrm{PM}$ that originated from various stationary resources in Noble County and entered tribal lands. The source sites selected for input included various refineries, power plants, and coke production plants. Stack height, terrain, wind direction and turbulence, horizontal distance, and various metrological conditions affected the dispersion of emissions. In total, $21 \%$ of these emissions reached the tribal area. This value fluctuated between winter and summer season [9].

The issue of accurate modeling of emissions has gained attention in Japan where models like the AIST-ADMER and METI-LIS have been developed for emission studies. The AIST-ADMER model by the National Institute of Ad- 
vanced Industrial Science and Technology incorporates metrological data and emission characteristics to calculate the average distribution of chemical concentration and exposure to general population over a wide area. METI-LIS, developed by Ministry of Economy, Trade, and Industry, emphasizes calculation of pollutant distribution released from lower and elevated sources under fixed and dynamic meteorological conditions. Razi (2012) used the AIST-ADMER model to estimate regional concentration and distribution of mercury in the central region of Honshu Island, home to various medium and heavy scale industries in Japan. The METI-LIS modeler was then used to study mercury distribution and concentration, in close vicinity to industrial zones, as released from two hypothetical coal power plants set $20 \mathrm{~km}$ apart. The model established that people located close to the emission source would be exposed to a higher level of mercury compared to the general population though exposure will not exceed the $0.04 \mathrm{ug} / \mathrm{m}^{3}$ level [10].

The issue of accurate prediction of emissions has also gained traction in India where $70 \%$ of electricity is generated from coal. Varma (2014) used the general Gaussian plume equation with various Pasquill-Gifford Stability classes, to determine concentration of $\mathrm{SO}_{2}, \mathrm{NO}_{\mathrm{x}}, \mathrm{CO}$ and Particle Matter emitted from the Rayalaseema Thermal Project at various grid points. Key findings show that concentration of suspended Particle Matter, $\mathrm{SO}_{2}$, and $\mathrm{CO}$ at 5 kilometers receptor point from source were greater, while $\mathrm{NO}_{\mathrm{x}}$ concentration was less than air quality standards. Further, $\mathrm{SO}_{2}$ concentration was higher at all receptor points ranging from 5 kilometers to 30 kilometers from source and its reduction needed further attention [11].

Ill-advised spatial placement of a coal power plant can carry severe consequences for the environment and public. Contradictory weather patterns over land can result in co-joining of emissions from multiple sources, which can drive distributed concentration of Particle Matter, $\mathrm{SO}_{2}$, and $\mathrm{NO}_{\mathrm{x}}$, above the normal air quality limit. Guttikunda (2014) study used the ENVIRON-Comprehensive air quality model with extensions for integrated assessment of gaseous and particle air pollution over an estimated geographical area of 24.52 million square kilometers and vertical height of $12 \mathrm{~km}$. Estimated emissions had a $+/-20 \%$ error due to non-uniform emissions reporting, operating conditions, and varying coal consumption rates. The key findings presented in the study were that there is a very strong correlation between clustering of power plants and high emissions concentration in local and intermediate geographical areas. Most coal plants are built near coalmines, irrespective of the fact that major population centers are in the immediate vicinity. Examples include Kobra cluster, Mundra cluster, and Mumbai cluster where population density can vary from $1000 / \mathrm{km}^{2}$ to $10,000 / \mathrm{km}^{2}$ [4].

This study was extremely helpful. It established a direct link between spatial placements of multiple coal power plants solely from a financial point of view including factors such as proximity to coal mines to reduce transportation costs, 
placing multiple units in a small area to share company resources, committing to minimum air quality standards. Nevertheless, it leads to worsening pollution crises due to high levels of emissions, conversion of various emissions into secondary pollutants and emission interactions. The study provided a mathematical relationship between particle matter concentration, morbidity and mortality rates. Number of estimated health effects $\delta E$ followed following relationship;

$$
\delta E=\sum_{i=1}^{\# \text { grids }} \beta \cdot \delta C_{i} \cdot \delta P O P i
$$

where $\beta$ is the concentration-response function (a $3.9 \%$ change in mortality rate per $4 \mathrm{ug} / \mathrm{m}^{3}$ of change in the $\mathrm{PM}_{2.5}$ concentration), $\delta C_{i}$ is change in concentration from ambient standards at grid $i$ and $\delta P O P i$ is the population exposed to incremental concentration $\delta C$ at grid $i[4]$.

Gourgue (2015) developed a model to study dispersion of $\mathrm{NO}_{\mathrm{x}}$ compounds released from CIBEL II Industrial unit boilers. The methodology used a general Gaussian pollutant dispersion equation in combination with Holland's equation, which accounts for an ultimate increase in plume height due to plume buoyancy as well as convective airflow. The model recognizes that plume dispersion was affected by hilly terrain and land sea boundaries. Natural barriers created by hilly terrain and wind patterns from the ocean drove $\mathrm{NO}_{\mathrm{x}}$ emission concentration as high as $140 \mathrm{ug} / \mathrm{m}^{3}$ in some areas [12].

Weather and terrain have a significant effect on dispersion of pollutants. In cold weather, the phenomena of temperature inversion impacts air quality. An inversion condition happens when stable, cooler air near the Earth's surface is followed by a layer of warmer air just above. Tran and Mölders (2012), University of Alaska, analyzed contribution of Particle Matter $\left(\mathrm{PM}_{2.5}\right)$ from point emission sources to the near surface air layer in certain areas in Fairbanks, Alaska, where air quality is worse than National Ambient Air Quality Standards (NAAQS), aka "Non-Attainment Areas". It has been often observed that Fairbanks' extremely cold winter creates a phenomenon of an inversion layer that results in formation of non-attainment areas [13]. In 2006, the National Ambient Air Quality Standards (NAAQS) tightened the criteria for Particle Matter $\left(\mathrm{PM}_{2.5}\right)$ concentration for 24-hour period to less than $35 \mathrm{ug} / \mathrm{m}^{3}$, which required a push for development of strategies for further emission controls. Since emission controls are expensive investments, a statistical study investigated if emissions from the point sources have a significant contribution in non-attainment areas.

The conclusion of the Trans \& Molders study follows that the Particle Matter $\left(\mathrm{PM}_{2.5}\right)$ concentration was high at breathing level very close to the point source, but emissions from point sources had a minor contribution on Particle Matter $\left(\mathrm{PM}_{2.5}\right)$ in non-attainment areas. Wind speed, temperature, and mixing heights have a strong influence on the Particle Matter's $\left(\mathrm{PM}_{2.5}\right)$ ability to stay or leave a non-attainment area. Nonpoint source emissions are major contributors of Particle Matter $\left(\mathrm{PM}_{2.5}\right)$ in non-attainment areas. Investment in emission controls at point sources would not guarantee any significant reduction of Particle Matter $\left(\mathrm{PM}_{2.5}\right)$ in non-attainment zones [13]. The study exemplifies that using envi- 
ronmental pollution models with statistical analysis can justify a financial cost. Since a financial investment decision would not yield any major benefit in terms of reducing impact on environment, a company can save that money for future use.

We have briefly discussed coal power plant involvement as a point source emitter of various pollutants. We have also discussed different modeling techniques that simulate dispersion of emitted pollutants over a wide geographical area, under various meteorological conditions. Due to commonality of Gaussian Plume Dispersion in various industrial plume dispersion modelers, as well as its robust simplistic equation, we have also decided to use it in our methodology. The Gaussian plume dispersion Equation (4) is based upon the advective-diffusive Equation (2), which explains transfer and diffusion of pollutants from instantaneous sources.

$$
\partial C \frac{\partial C}{\partial t}+\operatorname{div}(C V)=\nabla(K \nabla C)+R i+Q \delta\left(t-t_{0}\right) \delta\left(x-x_{0}\right) \delta\left(y-y_{0}\right) \delta\left(z-z_{0}\right)
$$

In the above advective-diffusive equation $C$ is the mass concentration of pollutant, $V$ is wind velocity vector, $K$ is turbulent diffusivity tensor, $R$ represents chemical/photochemical transformation, $Q$ is the source term, $\mathrm{t}$ is time at which emission occurred and $x_{0}, y_{0}, z_{0}$ are emission source coordinates. Under continuous emission, wind velocity, and turbulent diffusivity, the advective-diffusive equation transforms into the Gaussian plume dispersion equation [14]. The Gaussian plume model is a steady state model, due to the emission rate remaining continuous. However, a time dependent puff model is used for non-continuous emissions with varying wind direction and velocity. To account for the impact of air turbulence on distribution of airborne contaminants, dispersion coefficients from Pasquill-Gifford-Turner's six stability classes (A - F) are used with the Gaussian plume dispersion equation. Stability is a qualitative atmospheric character, which governs the vertical motion of the air tract. In an unstable atmosphere, the turbulence is positive (high). In a neutral atmosphere, it is zero; while in a stable atmosphere, it is suppressed [15].

\subsection{Health Impact}

A typical coal power plant of $600 \mathrm{MW}$ can introduce up to 3.5 million tons of $\mathrm{CO}_{2}$ into the atmosphere each year. On the same note, an uncontrolled power plant can emit up to 14,100 tons of $\mathrm{SO}_{2} 10,300$ tons of $\mathrm{NO}_{\mathrm{x}}, 220$ tons of volatile organic matter (VOC), 720 tons of CO, $220 \mathrm{lbs}$ of arsenic, $170 \mathrm{lbs}$ of mercury, $114 \mathrm{lbs}$ of lead, and $4 \mathrm{lbs}$ of cadmium [16]. A case study published by Green Peace Research Labs, Exeter, UK, on "Hazardous Emissions from Philippine Coal-fired Power Plants" also mentions the presence of Chromium, Cobalt, Zinc, Nickel, and Copper in fly ash from the Sual, Mauban, and Masinloc coal power plants [17].

According to the Environmental Protection Agency (EPA), when it comes to atmospheric pollution, power plants, in general, are responsible for $50 \%$ Mer- 
cury, 22\% Chromium, 62\% Arsenic, 28\% Nickel, 60\% SO , $_{2}$ 77\% Acidic Rain, and $13 \% \mathrm{NO}_{\mathrm{x}}$ emissions [18]. The EPA lists Nickel dust as a potential carcinogen [19]. The distribution of organic, inorganic, and metallic compounds in coal power plant emissions depend upon a multitude of factors, such as coal type, operating temperature of the boiler, the age of the equipment, and the pre-burn processing of the coal.

\subsection{Coal Transportation}

The biggest expense in a coal power plant operation is the raw material. Approximately 0.454 metric tons $(454 \mathrm{~kg})$ of coal can generate one megawatt of electricity per hour [20]. The US Energy Information Administration notes the average price of coal in 2015 was $\$ 29.20$ per ton.

In a breakdown of coal expenses, transportation makes up the largest portion. Total delivery cost in 2014 for a ton of coal stood around \$18.53/ton [20]. That equates to about $39 \%$ of total raw material expenses. Figure 2 lists the average commodity and transportation cost (\$/ton) for coal in 2008-2014. Nominal transportation cost for coal from year 2001 to 2008 increased from $\$ 0.025$ to $\$ 0.040$ per ton-mile [21].

To lower transportation costs, coal power plants are often built near coalmines [22]. It is imperative from a financial standpoint that a coal power plant, which is consuming tons of coal per hour, be located near a coalmine to minimize the operational cost. The cost of coal logistics plays a critical role in determining the feasibility of operating a coal power plant. In some cases, the logistics costs are more expensive than mining.

\subsection{Electric Transmission Losses}

Electric transmission from a power plant to regional sub-station is done using high voltage lines with ratings on these lines in the range from $132 \mathrm{kV}$ to $755 \mathrm{kV}$. Electric distribution to local consumers begins after high $\mathrm{kV}$ is stepped down to at most $132 \mathrm{kV}$ at a regional substation. A single regional sub-station can serve up to 200 houses in urban areas [23]. In total, transmission accounts for $17 \%$ of total electric distribution losses from power plant to consumers. Technical losses

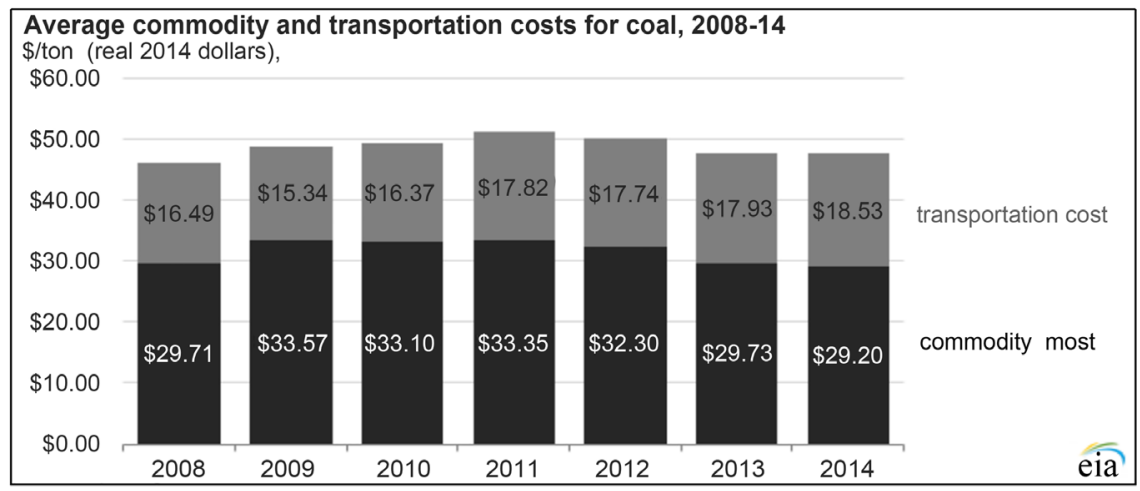

Figure 2. Average coal commodity and transportation cost [20]. 
in transmission are categorized in terms of permanent and variable losses. Permanent technical losses range between $25 \%$ and $33 \%$ on distribution networks. Examples include corona losses, dielectric losses, open circuit losses, and leakage current losses, etc. Technical variable losses are proportionate to the square of current in a given network. Examples include impedance losses, losses due to contact resistance, and Joule losses per voltage level, etc. [24].

\section{Corona losses}

The phenomena of Corona discharge are composed of a cumulative ionization process. Production of these ions extracts energy from the transmission supply and thus contribute to net electrical losses [25]. Factors that affect corona losses are atmosphere, conductor size, and spacing between conductors and line voltage. Corona losses above disruptive voltage are quantified using Equation (3):

$$
P_{c}=\frac{212.4}{\delta}(f+25)\left(V_{p}-U_{c}\right)^{2} \sqrt{\frac{r}{d} \times 10^{-5}}
$$

where $P_{c}$ is power loss, $V_{p}$ is phase to neutral voltage, $U_{c}$ is disruptive critical voltage, $f$ is supply frequency, $r$ is radius of transmission line, and $\delta$ is density of air.

\section{Ohmic losses}

Ohmic loss is heat generated by a wire due to its resistance to the flow of current. Magnitude of ohmic loss is directly proportional to the length of the transmission line $(\mathrm{m})$, wire resistance $(\mathrm{ohm} / \mathrm{m})$ and square of electric current (A) [26].

The losses described in this section were incorporated in the simulation model due to finance factor. The line losses can cost both the consumer and producer valuable capital over time, and, since these losses are proximity based, the best way to mitigate these losses is to optimally place a power plant near high demand customers.

\subsection{Location Analysis}

Location analysis refers to modeling of the class of problems best designated as deployment of facilities in a provided space. Distances between the facility and customers can be calculated using rectilinear, Euclidean, or Chebyshev principles [27]. In a network setting, the distance between two points present on the network is typically calculated using the shortest route from a set of given arcs. Classes of location objectives can be as follow:

- Pull Problem (The objective function desires on minimizing the proximity between facilities and customer).

- Capture Problem (The facility imbeds the cost of transportation in the commodity prices).

- Push Problem (The objective function desires maximizing the distances between facilities and customer).

- Equity (Attempt to have similar distances between multiple facilities and the customer). 
- Free Entry Problem (A facility location problem that minimizes the sum of plant opening costs and distribution costs whereas the total number of facilities is calculated as consequence of minimum cost solution).

- Least Set Cover Problems [27].

In a single facility setup, the ultimate objective of location analysis is to find a "point" on a planer grid that minimizes the sum of total transportation cost to several customers.

This objective problem can be represented by the Center of Gravity approach. The Center of Gravity approach provides a $x$-and- $y$ coordinate solution for setting up a new facility with the lowest total transportation cost. The Center of Gravity approach, however, does not take into consideration the real-life constraints. For example, the distances between facility and customers may be taken as straight-line distances whereas a path from point A to point $\mathrm{B}$ may be best represented by a network. They do not consider the volatility in set up costs associated with various possible locations. The volume of product flow assigned to each customer is represented by a static value, whereas the product demand may be subject to trend or seasonality [28].

Another tool for facility location problem solving is mixed integer linear programming. In mixed integer linear programming, the decision variables are constrained to be in integer values at an optimal solution. The mixed integer linear programming is considered non-convex problems, which can be solved using a Branch and Bound technique [29]. Mixed integer linear programming has the capability to optimally deal with the issue of fixed cost while insuring that customer demand is met on a given network. The new location for a facility can be best expressed with an objective function that minimizes the fixed and linear variable costs to transfer all products from facility to customers under various numbers of constraints. With increased number of constraints, the mixed integer linear programming can be highly exhaustive in terms of computational demand and an optimal solution is not always guaranteed [28].

If optimality is not the core requirement when searching for a new location, heuristic methods can provide a sub-optimal solution within a reasonable processing time. Other location search techniques are guided linear programming, dynamic warehouse location, the spatial interaction model, and multi criteria decision analysis.

In this research we have used a combination of "push" and "pull" location analysis strategy to calculate transmission losses and coal logistics cost with distances between power plant and stakeholders best represented by a network. The pull strategy will focus on finding a location, where the combined cost of electric transmission losses and coal delivery can be minimized. The pull strategy is suitable for this case since its main objective is to reduce the distance between customers and supplier. However, in our research, the objective function aims to minimize the combined electric transmission and coal logistics cost using a unit cost weight per length. This approach will ensure that on a given network the 
coal power plant is located closest to the chief electric customer. The same idea will apply to a coalmine providing the highest percentage of coal to power plant.

The push strategy will focus on minimizing emission exposure by maximizing distances between power plant and customers. The push strategy is suitable in this case since its main objective is to drive as much reasonable distance as possible, between coal power plant and customer. The push strategy is based on binary decision making to allocate the maximum distance between emission source and customer such that the pollutant exposure to that customers is less than NIOSH threshold for that pollutant. The maximum separation that can be achieved, however, is governed by the downwind range of Gaussian plume dispersion model.

\section{Methodology}

The methodology section is primarily composed of a Java based simulation using dynamic programming strategy. Dynamic programming is a useful mathematical technique for making a sequence of interrelated decisions. The aim of the methodology is constantly improving the objective function of minimizing the electric transmission losses and coal logistics cost under environmental constraints.

The methodology is simulation based due to dynamic range of several variables. Simulation is especially helpful in measuring and predicting the effect of change in value of individual element onto the entire system [30]. For example, the wind speed, the stack height, the exhaust velocity and temperature of emissions can take a range of different numeric values, resulting in various possible locations for coal power plant's placement. In addition, the shear amount of computations and visual projection makes the manual calculation completely infeasible. For example, a $20 \mathrm{~km} \times 20 \mathrm{~km}$ Gaussian plume contour grid with a resolution factor of $1 / 2 \mathrm{~km}$ contains about 1600 receptor points. To calculate resultant plume concentration for any given plume interaction with a different source modeled at identical grid size, can require up to 2,560,000 calculations per grid point. Since there are 10,000 grid points on a $100 \mathrm{~km} \times 100 \mathrm{~km}$ grid with resolution factor of one kilometer, the total amount of computations is enormous and simulation methodology can thus provide the best tool to deal with the problem.

\subsection{Step Wise Calculation Summary}

The program starts with initialization of static locations of multiple stakeholders, i.e. customers, supplier, and resources. Pollution dispersion equations are initialized for current and future power plants, followed by integral placement of the future power plant on all possible locations of a $2 \mathrm{D}$-spatial grid, with the relevant costs of electric transmission and coal transportation calculated at each location. A key point is that the algorithm calculates the shortest possible network for electric transmission from power plant to consumers. 
At each grid point on the map, the program calculates the costs related to transmission losses and coal distribution, as well as the magnitude of emission's concentrations of the pollutants at ground level. Useful data is saved in a declared holding variable (integer, float, array) and during each step of the program, a minimum cost function is run to either keep or update the holding variables. The ultimate objective of the program is to find a compromized location for placing a new power plant, which ensures minimum cost of operation for coal power plant and with the least amount of pollutant exposure to the general population.

\section{Inputs}

1) Location coordinates of residential and commercial consumers. Location of coalmines and any existing coal power plants.

2) Power plant's power output (that will determine coal usage) in units of MW.

3) Weather condition (wind speed, direction, solar elevation cloud cover, and temperature).

4) Height of stacks.

5) Transmission line physical properties. Unit cost of kWh charged by plant.

Outputs

1) Spatial $x$ and $y$ coordinates for coal power plant.

2) Net distance between coal power plant and consumers.

3) Net distance between coal power plant and coal mines.

4) Total cost for coal shipment.

5) Total cost of electric power transmission.

6) Visual display of emission concentration contours from coal power plant.

Objective Functions

Min: Exposure of power plant emissions to populations at various locations on a grid map.

Min : $\sum_{1}^{n}$ Cost of electric transmission losses $+\sum_{1}^{m}$ Coal transportation cost .

where $n$ is number of customers and $m$ is number of coal mines.

Constraints

$0 \mathrm{~km}, 0 \mathrm{~km}<$ Grid $x, y<100 \mathrm{~km}, 100 \mathrm{~km}$.

$x_{i \ldots n^{\prime}}, y_{i \ldots n^{\prime}}$ Concentration of $\mathrm{SO}_{2}, \mathrm{NO}_{\mathrm{x}}, \mathrm{PM}_{2.5} \& \mathrm{PM}_{10}<$ EPA Threshold.

Gaussian dispersion model

The Gaussian dispersion model is based upon the Gaussian distribution principle, where the width of the plume is determined by the standard deviation of longitudinal and vertical axes which in turn are dependent on environmental stability, class and travel time. The concentration of particle matter in microgram/cubic meter, at any location $x, y$ from the source can be calculated using the following Equation (4) [31]:

$$
C(x, y, z)=\frac{Q}{2 \pi U_{p} \sigma_{y} \sigma_{z}} \exp \left(-\frac{y^{2}}{2 \sigma_{y}^{2}}\right)\left[\exp \left(-\frac{\left(z-H_{p}\right)^{2}}{2 \sigma_{z}^{2}}\right)+\exp \left(-\frac{\left(z+H_{p}\right)^{2}}{2 \sigma_{z}^{2}}\right)\right](4)
$$


where $Q$ is emission rate of gas, $U_{p}$ is mean wind speed at the stack height, $H_{p}$ is sum of the actual stack height "Hs" plus any plume rise $\Delta H$ due to initial buoyancy or momentum of release; $z$ is the vertical distance from ground level, $y$ is the cross-wind distance from stack, $\sigma_{y}, \sigma_{z}$ is the standard deviation of concentration distributions in the crosswind and vertical directions.

\section{Euclidian distance}

Distance between two grid points on a two dimensional grid can be calculated using Equation (5):

$$
\text { Distance }=\sqrt{\left(x_{2}-x_{1}\right)^{2}+\left(y_{2}-y_{1}\right)^{2}}
$$

Coal shipment cost to power plant is calculated using Equation (6):

Cost $=$ Distance $($ Miles $) \times \frac{\text { Delivery Charge }}{(\text { Mile }- \text { Ton of coal })}$ charged by shipment company (6)

Electric Transmission Cost to Consumers is calculated using Equation (7):

$$
\operatorname{Losses}(\$)=\sum_{i=1}^{n} \text { Technical losses } \frac{\mathrm{kW}}{\mathrm{km}} \text {. Electric load } \cdot \text { Distance }(\mathrm{km})
$$

where $n$ is total number of customers; Technical losses equal resistive losses plus corona losses.

\section{AC power losses}

The main costs associated with AC Power Transmission are Resistive and Corona Losses. On average, $6.8 \%$ of total power generated gets wasted in these losses [32].

Resistive losses

$$
\% P_{\mathrm{RLOSS}}=\frac{P(0)-P(z)}{P(0)}=1-e^{-z R_{l} /(L c)}
$$

where $\% P_{\mathrm{RLOSs}}$ is percentage power loss; difference between initial amount of power minus amount of power delivered at any point on the transmission line, $Z$ is distance in meters, $R_{l}$ is resistance per unit length, $L$ is inductance/unit length, $c$ is speed of light.

$$
\delta=\frac{1}{\sqrt{\pi \int \mu_{o} \sigma}}
$$

where $\delta$ wire skin depth, $\mu_{o}$ is Permeability of free space, $\sigma$ is conductivity of metal.

$$
R_{l}=\frac{I_{B}}{2 \pi a \sigma \delta}
$$

where $I_{B}$ is Bessel correction factor and $a$ is wire radius

$$
L=\frac{\mu}{\pi} \ln \left(\frac{d}{a}\right)
$$

where $d$ is line separation.

Corona losses

$$
P=\frac{k_{o}}{k_{d}}(f+25) \sqrt{\frac{a}{d}}\left[V_{o}-g_{o} k_{i} a k_{d} \ln \left(\frac{d}{a}\right)\right]^{2} \cdot 10^{-5} \mathrm{~kW} / \mathrm{km}
$$


where $P$ is Corona loss $\mathrm{kW} / \mathrm{km} /$ line, $k_{o}$ is fixed constant, $k_{d}$ is Norm Air Density Factor, $f$ is frequency, $V_{o}$ is line voltage to neutral, $g_{o}$ is disruptive gradient of air, $k_{i}$ is wire irregularity factor, $k_{d}$ is normalized air density factor [32].

\subsection{Simulation Design}

The simulation uses a dynamic programming principle to choose an appropriate location for a power plant to minimize the electric distribution losses and coal transportation cost while ensuring the general public's exposure to a given pollutant stays below the National Ambient Air Quality Standards (NIOSH) threshold. The simulation is developed using Processing Language as the primary platform. The simulation is primarily composed of the following parts:

1) 2-Dimensional grid space $(100 \mathrm{~km} \times 100 \mathrm{~km})$ with grid resolution of $1 \mathrm{~km}$.

2) 20 customers spread randomly with integer-based $x, y$ spatial values.

3) Three coalmines clustered together within a $30 \mathrm{~km}$ vicinity of each other.

4) One existing and one new coal power plant with individual electric generation capacity, coal consumption, stack diameter, and stack height.

5) 2-Dimensional Gaussian plume chemical dispersion contours for a downwind range of $20 \mathrm{~km}$, with a 90-degree East wind and a receptor resolution of $500 \mathrm{~m}$. The horizontal and vertical dispersion coefficient for atmospheric stability classes A, B, C, D, E, and F is used with the Gaussian plume dispersion equation to calculate the dispersion concentration of pollutants in the downwind range at an elevation of " 0 " $\mathrm{m}$.

6) In the search process for a viable location for a new power plant, if the chemical dispersion contours overlap with a customer location and the chemical concentration is greater than the EPA threshold, it is acknowledged for further processing. The simulation can also successfully detect interaction between two power plant emissions and adjust the overlapping contours of chemical concentration accordingly.

7) Electric demand from each customer is represented in megawatts. Demand is chosen as a random integer value ranging from one megawatt to 100 megawatts.

8) Prim's algorithm is applied to find a minimum spanning tree between cities and a new power plant. A minimum spanning tree ensures that the total distance of all edges, connecting the cities and power plant, is minimized. The reason to use Prim's algorithm is due to its simplistic nature, availability of code for processing language software, running time complexity of $O\left(n^{2}\right)$, ability to start a minimum spanning tree from a given vertex and suitability to calculate the net electrical losses by back tracking on the resultant minimum spanning tree. The Kruskal algorithm does not guarantee a start from a given vertex, and the coding complexity of Sollin's algorithm made it non-preferential for usage [33] [34] [35].

9) Prim's algorithm is also applied to find a minimum spanning tree between 
the power plant and the coalmines.

10) Backtracking load transfer. A non-linear arrangement is used to calculate the cost of electric distribution losses from power plant to various customers located on the minimum spanning tree. The net electric load from the source (Power Plant) reduces in a step-wise function as each customer's demand on the network is satisfied; this results in non-linear cost reduction proportion to scale of deliveries. The net cost of electrical losses is calculated by back tracking on the minimum spanning tree produced using Prim's algorithm; start with the terminal nodes (Customers) and keep making head-ways to the root node (Power Plant).

The concept of "Backtracking load transfer" to calculate the cost of electrical losses is more "optimal" than concepts we found using the "average" approach. The average cost can be calculated simply by multiplying given line losses value for corresponding net electric load, by the total network distance. However, the "average" approach does not represent realistic application since the line losses cost calculated are significantly higher, as compared to "Backtracking load transfer" strategy.

11) The simulation tests all 10,000-location points for a candidate solution.

This marks the conclusion of the methodology section of the research project. The next section deals with data analysis and results. Section 4 focuses on validation of Prim's algorithm used to create minimum spanning tree, validation of Gaussian plume dispersion models under atmospheric condition A - F, coal logistics and transmission line resistive and corona losses.

\section{Data Analysis and Results}

The proposed methodology's main components are minimum spanning trees, respective costs for minimum spanning tree network, Gaussian plume dispersion modeling and emissions interaction. The primary algorithm used for minimum spanning tree is the Prim's algorithm. A Prim's algorithm example provided in Network Flows Theory, Algorithms, and Application [36] is first validated using R-software. Upon a successful match between the reference example and the R-output, a complete graph of six vertices is created in the simulation as shown in Figure 3(A). Application of Prim's algorithm produced a minimum spanning tree with a total distance of $80.64 \mathrm{~km}$, as shown in Figure 3(B). This total distance of 80.64 is then successfully validated by running Prim's algorithm on the Figure 3(A) (complete graph) using R-software-Optrees package [37].

The respective cost of electric delivery on minimum spanning tree is calculated by iteratively back-tracking from the terminal node to parent node. At each iteration, distance between various terminal nodes and corresponding parent nodes is calculated and depending on the magnitude of electric load between any two given points, the corresponding cost of corona and ohmic losses is calculated. Upon conclusion of an iteration, the terminal nodes are pruned, giving way to respective parent node transformation to terminal node. This process is 


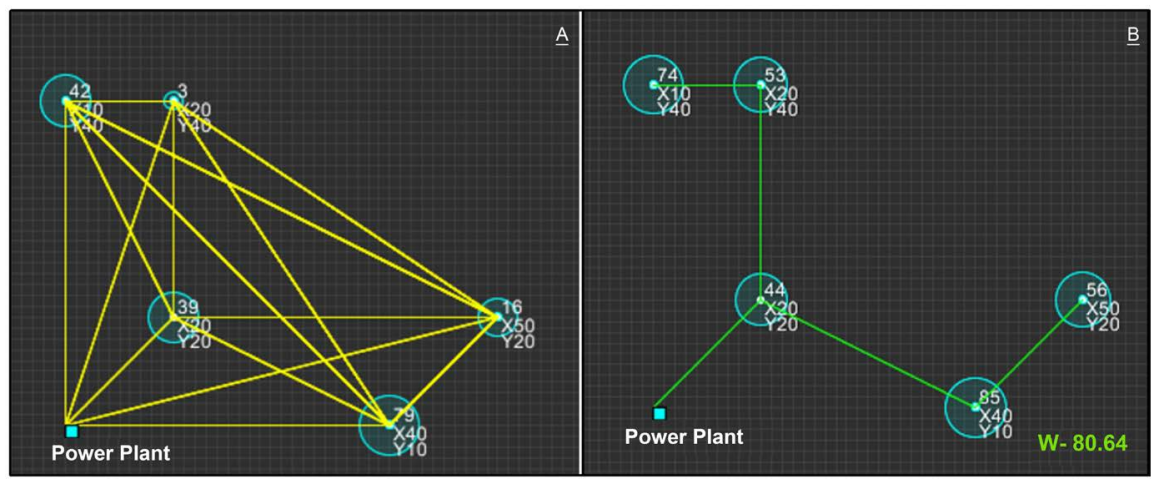

Figure 3. (A-Left) A complete graph representing all possible direct paths between cities and a power plant. (B-Right) Visual output of Prim's minimum spanning tree with total path distance of $80.64 \mathrm{~km}$.

repeated until the only node left is the root node (coal power plant). In the validation process of back-tracking strategy, the Prim's minimum spanning tree from Figure $3(\mathrm{~B})$ is used; it has total electric demand from five customers set equal to $213 \mathrm{MW}$. Electric power is generated at the power plant and channeled to cities using a single $765 \mathrm{kV}$ transmission line. Total power demand by five cities equals $213,000 \mathrm{kWh}$, which equates to hourly value of $\$ 29,820$ (at a rate of 14 cents $/ \mathrm{kWh}$ ). Net resistive and Corona Losses equate to a cost of $\$ 329.41$ to transmit $213 \mathrm{MW}$ power over a total transmission distance of $80.64 \mathrm{KM}$. In terms of dollar value, the transmission losses are only $1.105 \%$ of the total value of electric power generated. Figure 4 illustrates the process of cost calculation using back-tracking strategy.

The validation process for plume dispersion starts by calculating the effective height of buoyancy and momentum dominated plume using Briggs plume rise equation [38]. Simulation output indicates that for a stack height of $30.48 \mathrm{~m}$ with emission rate of $28.85 \mathrm{~g} / \mathrm{s}$, exit velocity of $18.31 \mathrm{~m} / \mathrm{s}$, exhaust exit temperature of the plume of $372.04 \mathrm{~K}$, wind speed at stack height of $3 \mathrm{~m} / \mathrm{s}$ and ambient temperature of $285 \mathrm{~K}$ at stack height, the effective height of the buoyancy-dominated plume is $419.26 \mathrm{~m}$ at a down-wind range of $1213.78 \mathrm{~m}$ from the stack structure. In the case of a momentum-dominated plume with all physical conditions being equal besides an exhaust exit temperature of $285 \mathrm{~K}$, the effective height of the momentum-dominated plume is $123.62 \mathrm{~m}$ at a down-wind range of $308.73 \mathrm{~m}$ from the stack structure, as shown in Figure 5.

The Gaussian plume dispersion model is simulated for atmospheric conditions A, B, C, D, E \& F for a $400 \mathrm{MW}$ coal power plant, emitting 28.85 grams of sulfur dioxide per second from a physical stack height of 30.48 meters with exhaust and atmospheric conditions described above. The simulated results from Gaussian plume modeling application are validated against EPA Screen3 model and Japanese METI-LIS model.

Screen 3 is the Environmental Protection Agency (EPA) single source Gaussian plume model that provides maximum ground level pollutant concentrations 


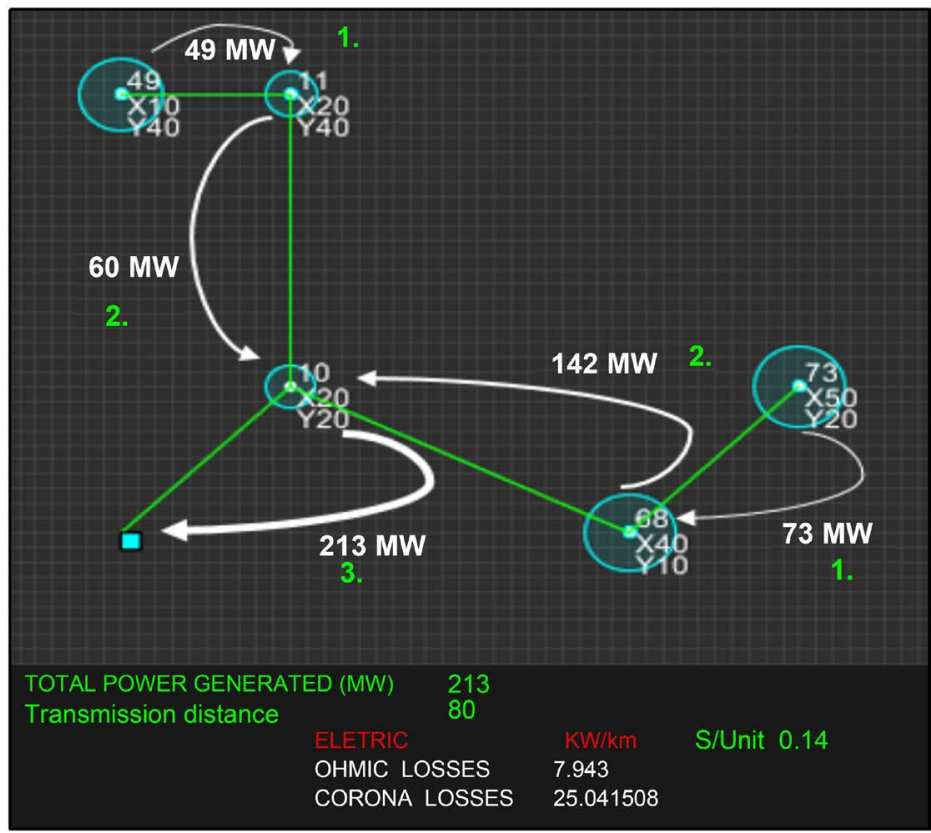

Figure 4. Visual conceptualization of back-tracking strategy.

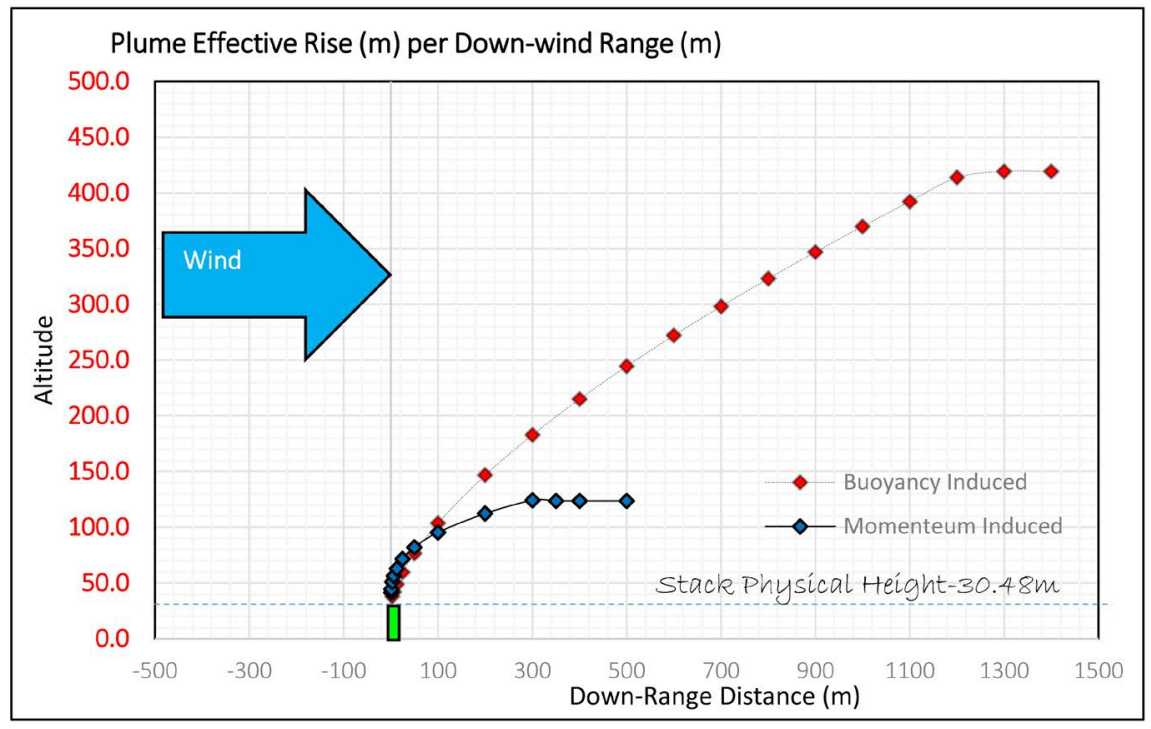

Figure 5. Graphical output representing (Buoyancy Dominated) and (Momentum Dominated) plume height evolution. The effective plume height value for both buoyancy and momentum dominated plume were successfully validated using EPA Screen3 model.

for flare, point, and volume sources. The model can provide pollutant concentration in the cavity zone as well as the concentration of pollutant due to inversion break up [8]. METI-LIS is a Gaussian dispersion model developed by the Japanese Ministry of Economy, Trade, and Industry (METI) and Japanese Research Center for Chemical Risk Management (CRM) based upon EPA ISC model. METI-LIS provides a simple solution to plume and puff models, and it incorporates the effect of downdraft around buildings. METI-LIS does not use Briggs equations for effective plume height but instead uses the CONCAWE eq- 
uation. The model can also calculate deposition concentration of particle matter [39].

The Gaussian plume dispersion application in simulation for atmospheric condition "A", provided maximum chemical concentration of $21.53 \mathrm{ug} / \mathrm{m}^{3}$ at a range of one kilometer from the stack, in the downwind direction. Comparatively, Screen3, under the very same conditions, provided a maximum emission concentration of $19.26 \mathrm{ug} / \mathrm{m}^{3}$ at a range of $0.874 \mathrm{~km}$. Meanwhile, METI-LIS provided a maximum concentration of $16.46 \mathrm{ug} / \mathrm{m}^{3} \mathrm{SO}_{2}$ at a range of $0.606 \mathrm{~km}$. See Figure 6. Regarding atmospheric condition " $\mathrm{B}$ ", maximum chemical concentration of $9.80 \mathrm{ug} / \mathrm{m}^{3}$ is calculated at a range of $3 \mathrm{~km}$ from stack in the downwind direction. Whereas, Screen3 provides a maximum concentration of $10.24 \mathrm{ug} / \mathrm{m}^{3}$ at a range of $2.424 \mathrm{~km}$ and METI-LIS provides maximum concentration of 13.49 $\mathrm{ug} / \mathrm{m}^{3} \mathrm{SO}_{2}$ at a range of $1.818 \mathrm{~km}$ from stack.

Simulation modeling for atmospheric condition " $\mathrm{C}$ ", provides maximum chemical concentration of $8.30 \mathrm{ug} / \mathrm{m}^{3}$ at a range of $6 \mathrm{~km}$ from the stack in a downwind direction. Relatively, Screen 3 model provides maximum concentration of $7.714 \mathrm{ug} / \mathrm{m}^{3}$ at a range of $4.879 \mathrm{~km}$ while METI-LIS respectively provides maximum concentration of $11.18 \mathrm{ug} / \mathrm{m}^{3} \mathrm{SO}_{2}$ at a range of $3.030 \mathrm{~km}$. Atmospheric condition " $\mathrm{D}$ " provides a maximum chemical concentration of 1.99 $\mathrm{ug} / \mathrm{m}^{3}$ at a range of $20 \mathrm{~km}$ from the stack in a downwind direction. Relatively, Screen 3 provides maximum concentration of $2.593 \mathrm{ug} / \mathrm{m}^{3}$ at a range of 20.250 $\mathrm{km}$ and METI-LIS provides respective maximum concentration of $4.718 \mathrm{ug} / \mathrm{m}^{3}$ $\mathrm{SO}_{2}$ at a range of $11.11 \mathrm{~km}$.

Atmospheric condition " $\mathrm{E}$ " provides a maximum chemical concentration of $10.22 \mathrm{ug} / \mathrm{m}^{3}$ at a range of $13 \mathrm{~km}$ from the stack in a downwind direction. Relatively, Screen 3 provides a maximum concentration of $12.03 \mathrm{ug} / \mathrm{m}^{3}$ at a range of $10 \mathrm{~km}$ and METI-LIS provides a maximum concentration of $2.76 \mathrm{ug} / \mathrm{m}^{3} \mathrm{SO}_{2}$ at a range of $20 \mathrm{~km}$. Lastly, atmospheric condition " $\mathrm{F}$ " provides a maximum chemical concentration of $6.26 \mathrm{ug} / \mathrm{m}^{3}$ at a range of $20 \mathrm{~km}$ from the stack in a downwind direction. Relatively, Screen3 provides a maximum concentration of 8.468 $\mathrm{ug} / \mathrm{m}^{3}$ at a range of $15 \mathrm{~km}$ and METI-LIS provides a maximum concentration of $0.5459 \mathrm{ug} / \mathrm{m}^{3} \mathrm{SO}_{2}$ at a range of $20 \mathrm{~km}$.

It can be observed that as we step from atmospheric condition A to F, moderate deviations start developing between the simulation results and Screen 3 in terms of maximum concentration and distance to maximum concentration. These deviations however are pronounced between the simulation results and METI-LIS results. The conclusion section includes further details on this subject.

Plume interaction is simply pollutants exhausted by multiple sources sharing the same spatial volume. Plume interaction is important. An individual source of interest may be spreading pollutants below the EPA threshold; however, the presence of multiple sources and their resultant interaction can end up driving local concentrations higher than the EPA threshold. Per problem 20 on page 52 of the EPA-Workbook of Atmospheric Dispersion Estimates, the final concen- 
tration of $\mathrm{SO}_{2}$ on a given receptor point is obtained by summation of individual pollutant concentrate emitted from a power plant and refinery at that given receptor point [40]. The same strategy is being applied in our simulation, where two coal power plants placed $5 \mathrm{KM}$ apart in the north-south direction are emitting the same amount of $\mathrm{SO}_{2}$ in the immediate east direction under atmospheric condition "A" as shown in Figure 7. The simulation provides a maximum chemical concentration of $21.510 \mathrm{ug} / \mathrm{m}^{3}$ at a range of one kilometer from the stack in a downwind direction for each power plant. However, at a range of $20 \mathrm{~km}$ the pollutant concentration on the Power plant (2) emission trail (centerline) is $19.60 \%$ higher than an individual power plant emission concentration.

Coal transportation cost validation is done using a simplified model containing only one coal power plant and three coalmines as depicted in Figure 8(A). The simplified model is based on the concept of Fermat point; a point in the triangle where sum of distances from vertices to the point is minimal [41]. This approach is akin to a 3-Point Steiner tree, where the coal mines represent three stationary points on a grid and the coal power plant is the extra intermediate vertex serving as a shared junction [35]. For each megawatt/hour generation, the coal power plant consumes 0.733 tons of coal per hour (operating efficiency of a power plant affects this relationship). Figure 8(A) represents the initial state of simulation with a $884 \mathrm{MW}$ power plant, located at location of $\left(x_{0}, y_{0}\right)$. Yellow lines represent the minimum spanning tree between the coal power plant and coalmines by the application of Prim's algorithm.

Each coal mine on the map contributes $33.33 \%$ or 216 tons to the total coal demand. The transportation cost is set at $\$ 0.042$ per ton $-\mathrm{km}$. The coal movement and related costs are as follows:

1) 216 tons of coal get transferred from (Coalx ${ }_{80}$, Coaly- $\left.{ }_{45}\right)$ location to $\left(\right.$ Coalx- ${ }_{75}$, Coaly- $\left.{ }_{75}\right)$ at a cost of $\$ 275.87$.

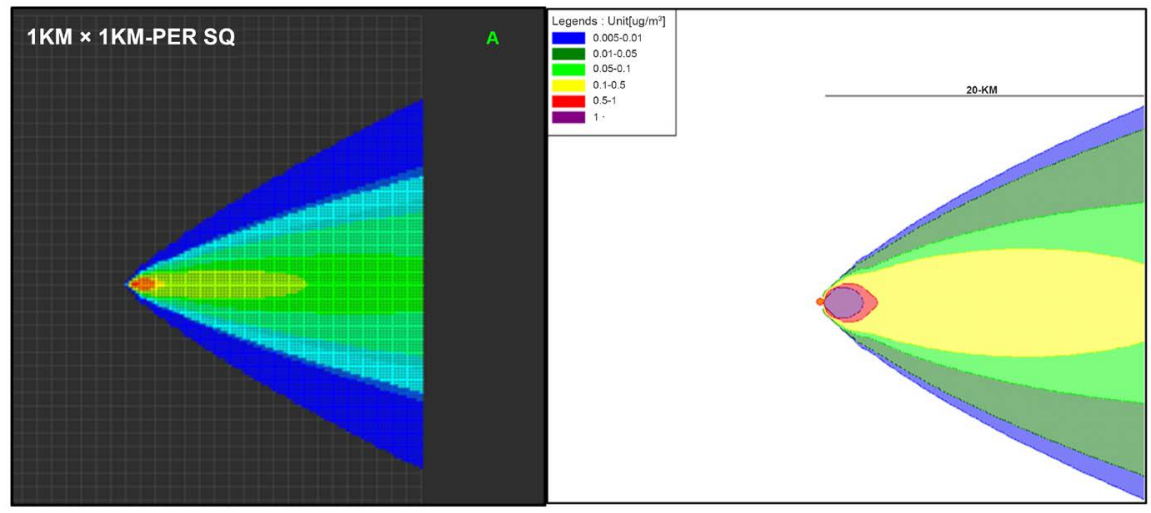

Figure 6. (Left) Visual representation of atmospheric pollutant dispersion under Pasquill-Gifford-Turner's atmospheric condition (A) up to downwind range of $20 \mathrm{~km}$. Maximum concentration of $21.53 \mathrm{ug} / \mathrm{m}^{3}$ predicted at range of $1 \mathrm{~km}$ downwind from emission source. (Right) METI-LIS Visual output of pollutant dispersion under same conditions with maximum concentration of $16.46 \mathrm{ug} / \mathrm{m}^{3}$ predicted at range of $0.606 \mathrm{~km}$ downwind from emission source. 


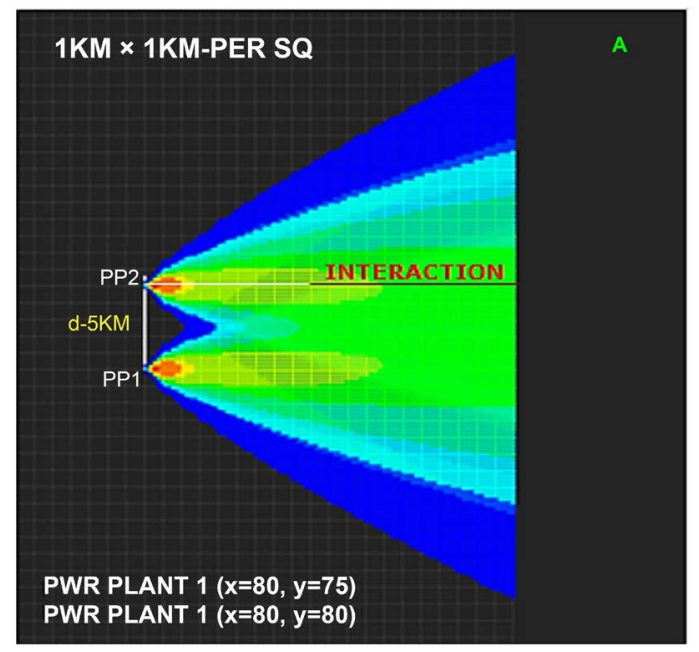

Figure 7. Plume interaction for Power plant (1) and Power plant (2) under atmospheric condition A up to downwind range of $20 \mathrm{~km}$. Distance between the Power plant (1) and (2) is $5 \mathrm{~km}$. ${ }^{*}$ Red color refers to areas of highest chemical concentration whereas the blue color represents areas of lowest Chemical concentration.

2) 432 tons of coal gets transferred from (Coalx $-_{75}$, Coaly- ${ }_{75}$ ) location to $\left(\right.$ Coalx- ${ }_{55}$, Coaly- $\left._{65}\right)$ at a cost of $\$ 405.69$.

3) 648 tons of coal gets transferred from $\left(\mathrm{Coalx}_{-55}\right.$, Coaly- $\left.{ }_{65}\right)$ location to (Power Plant $x_{-0}$, Power Plant $y_{-0}$ ) at a cost of $\$ 2317.44$.

4) Total cost to transfer all coal from three mines to the power plant is $\$ 2999$.

Upon conclusion of the simulation, the compromized location for the power plant is finalized at $\left(x_{69}, y_{65}\right)$ as shown in Figure $8(\mathrm{~B})$. The total transportation cost for coal delivery to the power plant is $\$ 439.49$ with a total delivery distance of $48.49 \mathrm{~km}$, as compared to initial state in Figure 8(A), which has a delivery distance of $137.92 \mathrm{~km}$ and delivery cost of $\$ 2999$.

The electric transmission losses are composed of resistive and corona losses. The resistive losses are a function of resistance/meter, inductance/meter, and frequency of the transmission line [32]. Loss ratio is calculated on a $1000 \mathrm{~m}$ aluminum transmission line with a conductivity value of $38.2 \times 10^{6}(\mathrm{~S} / \mathrm{m})$. Resistance per meter is inversely proportional to the radius and operating frequency of the wire, due to the phenomena of skin depth. A wire with a radius of 0.005 $\mathrm{m}$, operating at a frequency of $60 \mathrm{~Hz}$, has resistance of $8.72 \times 10^{-5} \mathrm{ohms} / \mathrm{m}$ while a wire of $0.035 \mathrm{~m}$ radius has a resistance of $1.25 \times 10^{-5} \mathrm{ohms} / \mathrm{m}$. See Figure 9 . This is a substantial $85.66 \%$ decrease in resistance.

In terms of power loss, a wire with a radius of $0.005 \mathrm{~m}$ operating at a frequency of $60 \mathrm{~Hz}$ has loss ratio of $9.56 \times 10^{-5}$ as compared to a wire of 0.035 m radius, which has a loss ratio of $1.84 \times 10^{-5}$ at the same frequency. See Figure 10 . This is a substantial $80.75 \%$ decrease in power loss. Corona Losses $(\mathrm{kW} / \mathrm{km} / \mathrm{line})$ are represented as a function of conductor radius $(\mathrm{cm})$ and disruptive critical voltage $(\mathrm{V})$ for a transmission line operating at a frequency of $60 \mathrm{~Hz}$ [32]. A disparity between conductor radius and disruptive critical voltage can result is higher than normal Corona Losses. 


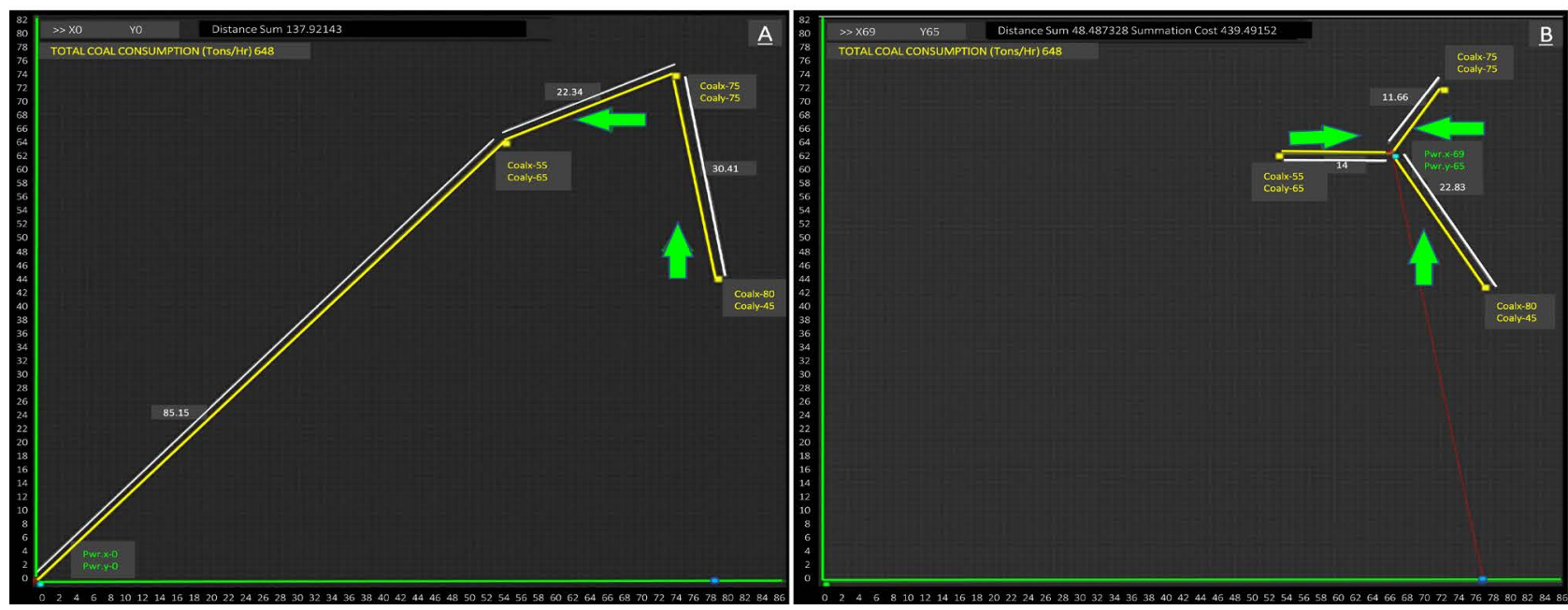

Figure 8. Coal transportation cost validation (Initial and Final State).

\section{Simulation Graphics Output}

The simulation is written in a Processing ${ }^{\circledR}$ software. Upon initialization, a display window appears, as shown in Figure 11. The new Power Plant (2), is placed on the grid $\left(x_{0}, y_{0}\right)$. The resolution factor selected for the Gaussian plume dispersion model is two receptor points per kilometer. Circles represent the cities (customers); a green line represents the minimum spanning tree to connect all customers with the Power Plant (2). Yellow squares represent coalmines.

The program after evaluation of all 10,000 grid points provides a compromised solution. The best location to place Power plant $(2)$ is $\left(x_{59}, y_{64}\right)$ as shown in Figure 12, denoted by "blue" square. The "green" square is an exclusive location for minimum electric transmission, while "yellow" square is exclusive for minimum coal delivery cost. The total electric losses and transportation cost associated with $\left(x_{59}, y_{64}\right)$ is $\$ 1859.68$, compared to $\$ 3050.64$ observed at the start of simulation (Figure 11).

\section{Conclusion and Recommendations}

\subsection{Conclusion}

Coal-based electric power currently holds the largest share in electricity generated from non-renewable resources. The major concern regarding the widespread use of coal power is the cofounded risk of its emissions being a detrimental health risk to the public. The biggest operational cost for a coal power plant is the coal and the cost of coal delivery to the power plant. Another addition to this complex problem is factoring the transmission losses a power plant faces due to the sum of distance between the power plant and the respective customers. In terms of location analysis, we face the following problem:

Given a grid of dimension $X_{(n)}, Y_{(n)}$, what location $(x, y)$ can provide us with minimum cost of electric transmission losses and coal delivery, while ensuring that public exposure to coal-based emissions stay below EPA thresholds. 


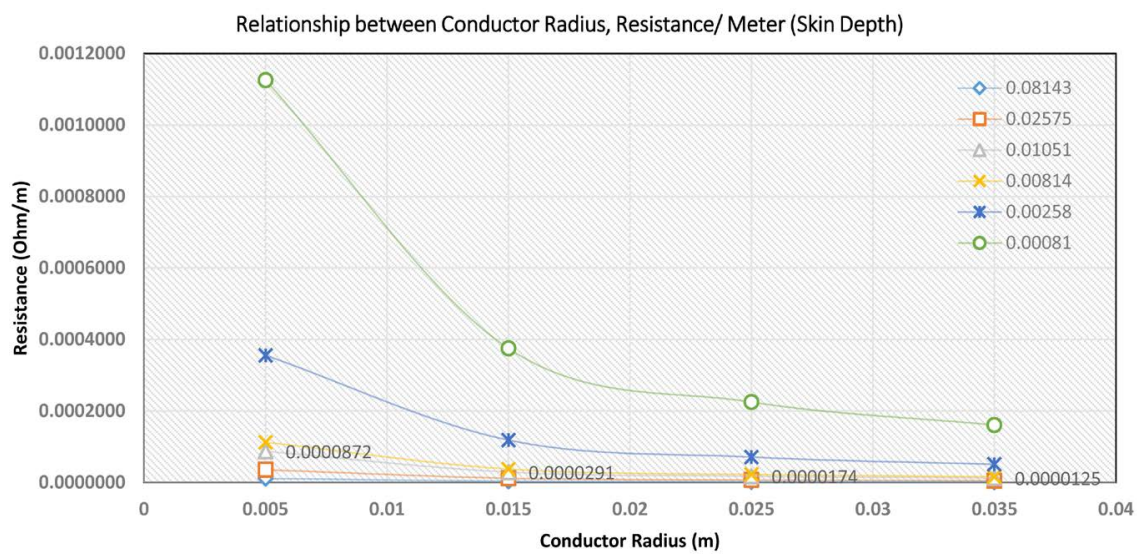

Figure 9. Graphical relationship between conductor radius and resistance/meter.

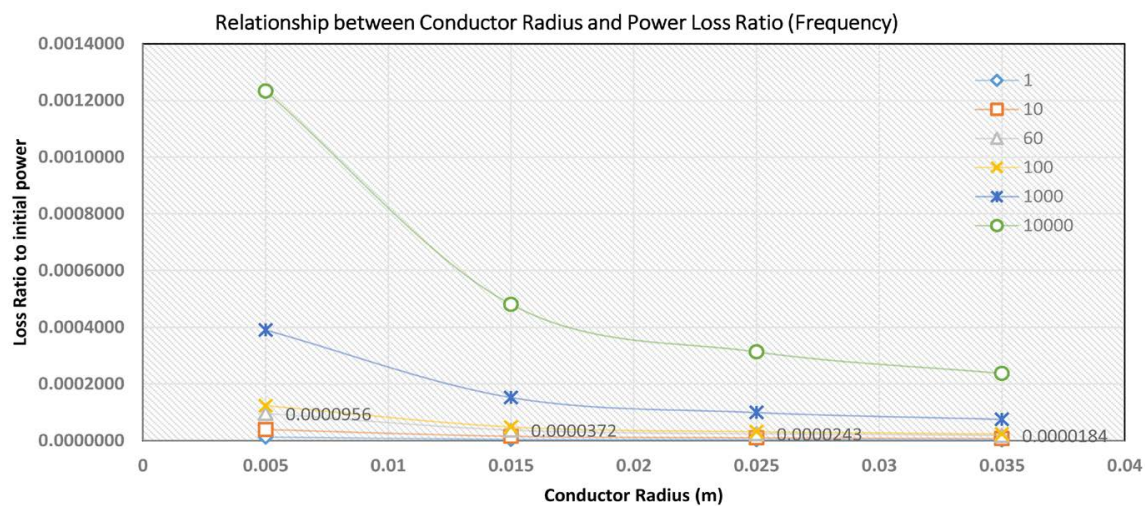

Figure 10. Graphical relationship between conductor radius and loss ratio at various frequencies.

In this study, we have successfully built a dynamic program, which simulates:

1) Coal power plant emission's dispersion, using a Gaussian Dispersion Model. The program has the capability to detect emission interaction between emissions of two coal power plants. The program can automatically block placement of a coal power plant near a city (customer), if the emission exposure to that customer is greater than a given EPA threshold.

2) A minimum spanning tree for electric transmission from a coal power plant to a given set of customers using Prim's algorithm. The distance between two points, as well as the electric load on that transmission line, influences transmission losses. To deal with non-linear electric load between a power plant and various customers, a backtracking load transfer strategy is implemented. Use of Prim's algorithm with backtracking load transfer strategy ensures a better location selection as compared to other location analysis methodologies such as center of gravity, load factor rating, and load distance technique.

3) A minimum spanning tree for coal deliveries between a given set of coalmines and a power plant.

The program uses an exhaustive search strategy to find the best possible location 


\section{Initial State}

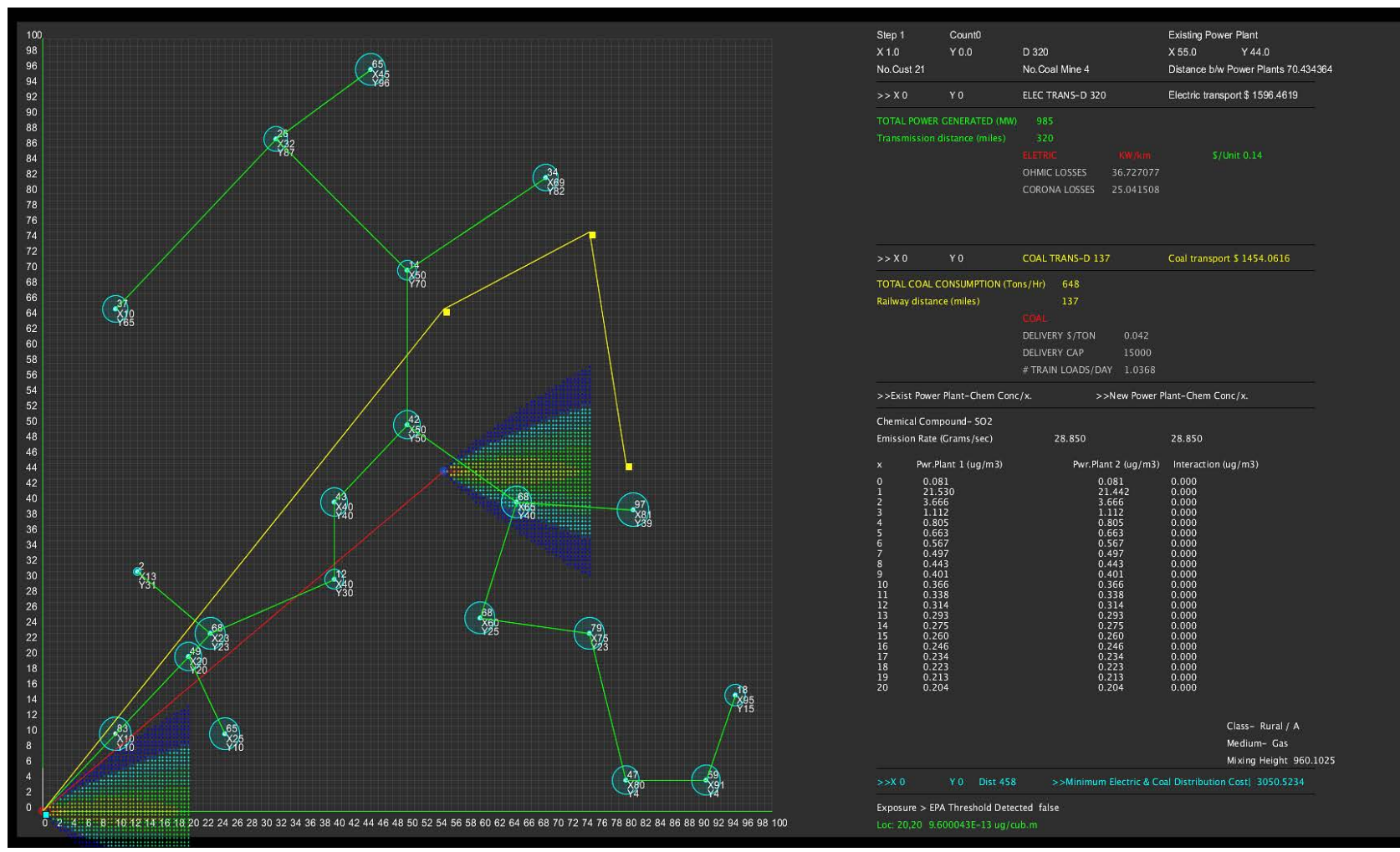

Figure 11. Display window of simulation upon initialization.

\section{Final State}

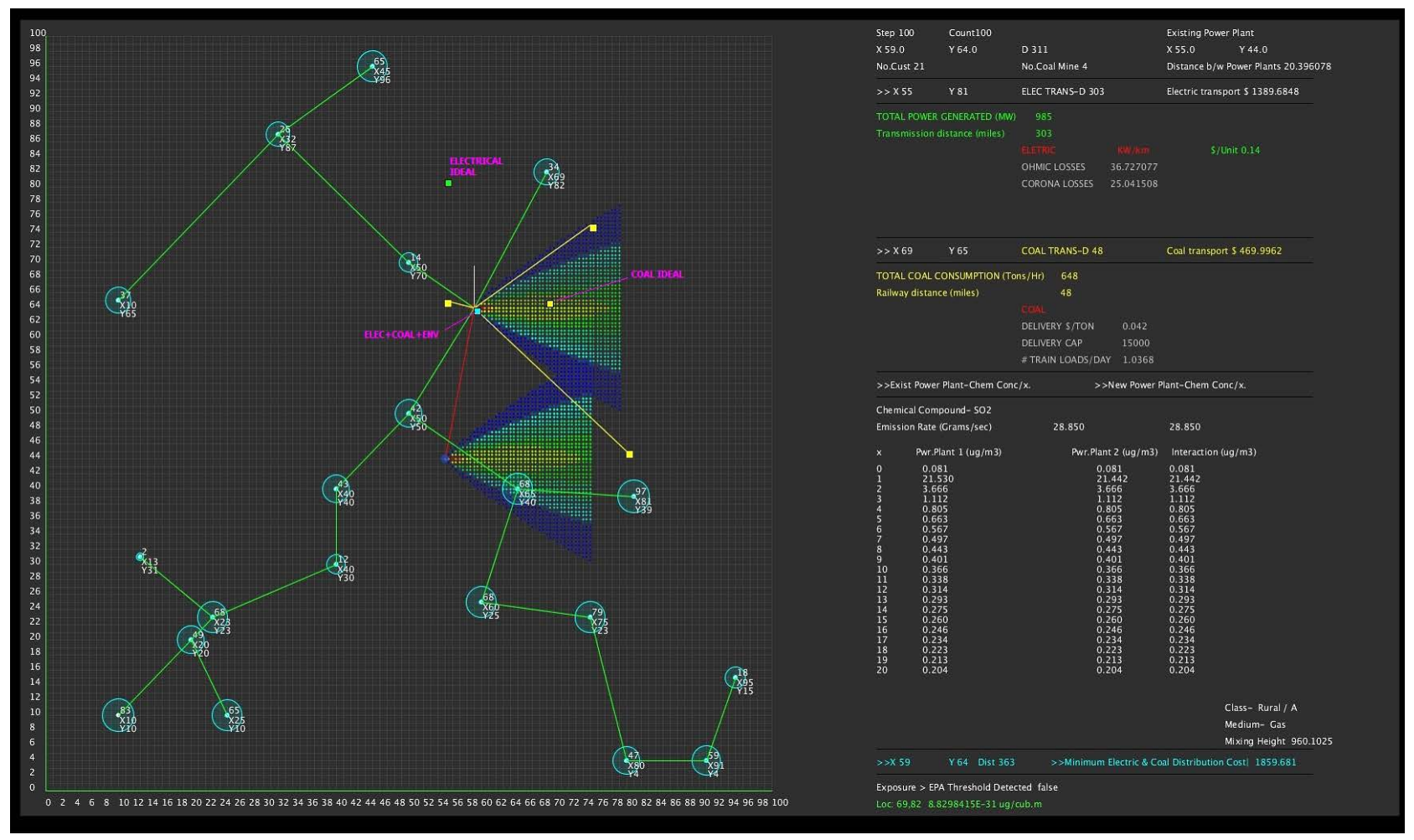

Figure 12. Display window of simulation upon finalization. 
for a new power plant. At each point on a $2 \mathrm{D}$ grid, the program first checks for emission interaction with another coal power plant and any respective customer. If the interaction exists with another coal power plant emission's, the program combines the value of both emissions for that grid point. If the interaction exists with a client, the program compares the respective emission concentration (both from individual or combined emission) against National Ambient Air Quality Standards (NIOSH) threshold value and the emission exposure' Boolean condition is declared.

The program then runs, Prim's algorithm between the coal power plant and the customers to find the shortest tree to connect all customers to the power plant with transmission lines. A backtracking load transfer strategy is used with Resistive and Corona Losses formulation to calculate the transmission losses. The transmission losses' value is transformed into dollar value and stored using a float variable. Prim's algorithm is then applied to calculate a minimum spanning tree to connect coalmines to the power plant. The coal delivery cost is calculated by multiplying the coal load in tonnage with delivery charge of moving one ton of coal, one kilometer. The combined cost of electric transmission losses and coal delivery are compared to the current stored minimum cost value. If the new value of cost is less than the current stored value, and the emission exposure Boolean state is "False", then the current cost value gets replaced by the new value, as well as the candidate location coordinates. The program has the capability to deal with up to 30 cities with exclusive coordinates as well as 10 coalmines for location analysis. The embedded Gaussian Dispersion Model can successfully simulate the plume dispersion model up to a range of $25 \mathrm{~km}$ from the point source, with a resolution factor of five receptor points per kilometer-the processing time required to complete testing of all 10,000 potential locations is in days.

Answering the research questions posed in the beginning of this paper, we determined that the following plume dispersion models can be successfully combined with the location optimization algorithm:

Environmental Protection Agency proposed screening model $>$ Screen3

Environmental Protection Agency comprehensive model $>$ ISC3

Japanese Ministry of Economy, Trade, and Industry > METI-LIS

However, during the validation process the residual between the programmed predicted results and METI-LIS were bit higher in terms of [distance to maximum pollutant concentration] or [concentration along the wind direction]. The validation discussion on the next pages includes an explanation.

The developed dynamic program uses Prim's algorithm to produce transmission and coal transportation network. The Prim's algorithm network with application of backtracking load transfer strategy provides less cost on both networks compared to other traditional location analysis strategies like center of gravity and load distance technique, etc. Since the program uses an exhaustive search strategy, it looks at all possible locations on a grid map. It is quite certain to find a better location compared to a random, greedy or meta-heuristic 
search strategy.

The program is built to sense plume concentration at ground level for a given customer during the search process. The user can select the threshold limit for a certain pollutant, and, if the ground level concentration in the search area is greater than the threshold for the respective coal power plant location on map, that position is eliminated for candidacy. However, an uncertainty factor rises when the Gaussian Model is used to predict plume concentration plume beyond 30 - $50 \mathrm{~km}$ downwind range. The model cannot guarantee that beyond $25 \mathrm{~km}$ any customer present in the plume line will be exposed to pollutant concentration less than the National Ambient Air Quality Standards (NAAQS) threshold.

For validation, the Gaussian plume dispersion results for atmospheric conditions A-F were tested against the EPA Screen3 model, as well as Japanese METI-LIS model. Deviation in simulation plume dispersion results was within $25 \%$ of the EPA Screen3 model, but, for the METI-LIS model, these deviations were much greater depending upon atmospheric conditions. The significant differences from the METI-LIS model, however, do not compromise the validity of our simulation since, in simulation, the effective plume height is calculated using the "Briggs" Equations while the METI-LIS model uses "Concawe" equations [39]. The Briggs equation does not take into consideration isobaric specific heat and density of gas.

Simulation's Prim's algorithm results are verified by using R-Statistics “Optrees" package. The results were an exact match, concluding that the coding of Prim's algorithm in the simulation program is correct.

\subsection{Recommendations}

The developed methodology offers a room for future improvements. Currently, the equations used for plume modeling are from the EPA ISC3 Model. However, it would be more appropriate to use EPA “AEROMOD” or "CALPUFF" models. AEROMOD and CALPUFF provide more robust ways of calculating the planetary boundary layer. The models also contain pre-processing capability for terrain and meteorological data with the ability to simulate dispersion over vast distances as well as chemical transformation of emission compounds. The current methodology operational environment is just two-dimensional. To better accommodate various geographical features such as "valleys" and "peaks", a three-dimensional operational environment is recommended.

In terms of financial feasibility, the grid search can be related to a "Net Present Value" (NPV) equation. Each location on the map can have an associated NPV value. In the current methodology, the customer locations are considered "static" with still demand throughout the simulation run. However, to better account for changes like rapid "urbanization" or "loss in population", demand structure can be made "dynamic".

The developed methodology uses Prim's algorithm for producing minimum spanning tree (MST), however distance related costs can be further minimized by application of "Steiner Tree". 


\section{Conflicts of Interest}

The authors declare no conflicts of interest regarding the publication of this paper.

\section{References}

[1] EIA (2018) What Is U.S. Electricity Generation by Energy Source? U.S. Energy Information Administration-EIA-Independent Statistics and Analysis. https://www.eia.gov/tools/faqs/faq.php?id=427\&t=3

[2] EIA (2017) International Energy Outlook. US Energy Information Administration, Rep. No. DOE/EIA-0484 (2017), 1-76.

[3] Alonso, F. and Greenwell, C.A. (2013) Underground vs. Overhead: Power Line Installation-Cost Comparison and Mitigation. Electric Light \& Power. https://www.elp.com/index.html

[4] Guttikunda, S.K. and Jawahar, P. (2014) Atmospheric Emissions and Pollution from the Coal-Fired Thermal Power Plants in India. Atmospheric Environment, 92, 449-460. https://doi.org/10.1016/j.atmosenv.2014.04.057

[5] Xie, L., Huang, Y. and Qin, P. (2016) Spatial Distribution of Coal Fired Power Plants in China. Environment for Development, Peking, EfD DP 16-25, 1-30.

[6] Aul, E. and Pechan, E. (1996) External Combustion Sources-Anthracite Coal Combustion Final Section. Environmental Protection Agency, Durham, 1-13, Rep.

[7] IEA Statistics (2014) Electricity Production from Coal Sources (\% of Total). The World Bank. https://data.worldbank.org/indicator/eg.elc.coal.zs

[8] EPA (2016) Air Quality Models. United States Environmental Protection Agency. https://www.epa.gov/scram/air-quality-models

[9] Alemayehu, D. and Hackett, F. (2015) Gaussian Dispersion Model to Estimate the Dispersion of Particulate Matters (Pm2.5) and Sulfur Dioxide (So2) Concentrations on Tribal Land, Oklahoma. American Journal of Environmental Sciences, 11, 440-449. https://doi.org/10.3844/ajessp.2015.440.449

[10] Razi, K.M. and Hiroshi, M. (2012) Modeling of Atmospheric Dispersion of Mercury from Coal-Fired Power Plants in Japan. Atmospheric Pollution Research, 3, 226-237. https://doi.org/10.5094/APR.2012.025

[11] Varma, S., Srimurali, M. and Varma, S. (2014) Prediction of Ground Level Concentrations of Air Pollutants Using Gaussian Model, Rayalaseema Thermal Power Project, Kadapa, A.P., India. Energy and Environmental Engineering, 91-97.

[12] Gourgue, H., Aharoune, A. and Ihlal, A. (2015) Dispersion of the NOx Emissions from Chimneys around Industrial Area: Case Study of the Company CIBEL II. Materials Today: Proceedings, 2, 4689-4693.

[13] Tran, H. N. and Mölders, N. (2012) Numerical Investigations on the Contribution of Point Source Emissions to the PM2.5 Concentrations in Fairbanks, Alaska. Atmospheric Pollution Research, 3, 199-210. https://doi.org/10.5094/APR.2012.022

[14] Awasthi, S., Khare, M. and Gargava, P. (2006) General Plume Dispersion Model (GPDM) for Point Source Emission. Environmental Modeling \& Assessment, 11, 267-276. https://doi.org/10.1007/s10666-006-9041-y

[15] Weiner, R.F. and Matthews, R.A. (2003) Environmental Engineering. 4th Edition, Elsevier Science, Burlington.

[16] Union of Concerned Scientists (2017) Coal and Air Pollution. Union of Concerned Scientists. 
https://www.ucsusa.org/clean-energy/coal-and-other-fossil-fuels/coal-air-pollution\# .WuHylfkvzIV

[17] Brigden, K. and Santillo, D. (2002) Hazardous Emissions from Philippine Coal-Fired Power Plants. Green Peace, Exeter, 1-21. http://www.greenpeace.org

[18] EPA (2017) Mercury and Air Toxics Standards. Cleaner Power Plants. United States Environmental Protection Agency. https://www.epa.gov/mats/cleaner-power-plants\#limits

[19] Geiger, A. and Cooper, J. (2010) Overview of Airborne Metals Regulations, Exposure Limits, Health Effects, and Contemporary Research. Environmental Protection Agency, Portland, 1-56. https://www3.epa.gov/ttnemc01/prelim/otm31appC.pdf

[20] U.S. Energy Information Administration (2016) Independent Statistics and Analysis. https://www.eia.gov/todayinenergy/detail.php?id=25092

[21] U.S. Energy Information Administration (2012) Independent Statistics and Analysis. https://www.eia.gov/coal/transportationrates/archive/2010/index.php

[22] EIA (2017) Coal Mining and Transportation. U.S. Energy Information Administration EIA Independent Statistics and Analysis. https://www.eia.gov/energyexplained/index.cfm?page=coal_mining

[23] Bond, S., Sims, S. and Dent, P. (2013) Towers, Turbines and Transmission Lines: Impacts on Property Value. John Wiley \& Sons, Hoboken. https://doi.org/10.1002/9781118533215

[24] Bhatti, S.S. and Haq, S.U. (2015) Electric Power Transmission and Distribution Losses Overview and Minimization in Pakistan. International Journal of Scientific \& Engineering Research, 6, 1108-1112.

[25] Tonmitr, K., Ratanabuntha, T., Tonmitr, N. and Kaneko, E. (2016) Reduction of Power Loss from Corona Phenomena in High Voltage Transmission Line 115 and $230 \mathrm{kV}$. Procedia Computer Science, 86, 381-384.

https://doi.org/10.1016/j.procs.2016.05.108

[26] Wong, L. (2011) A Review of Transmission Losses in Planning Studies. Electricity Analysis Office, California Energy Commission, Sacramento. http://www.energy.ca.gov/2011 publications/CEC-200-2011-009/CEC-200-2011-009. pdf

[27] Revelle, C. and Eiselt, H. (2005) Location Analysis: A Synthesis and Survey. European Journal of Operational Research, 165, 1-19. https://doi.org/10.1016/j.ejor.2003.11.032

[28] Ballou, R.H. (2004) Business Logistics Management: Planning, Organizing, and Controlling the Supply Chain. Prentice-Hall, Upper Saddle River.

[29] Frontline Systems, Inc. (2012) Optimization Problem Types-Mixed-Integer and Constraint Programming. Frontline Systems. https://www.solver.com/integer-constraint-programming

[30] Britannica, T.E. (2017) Computer Simulation. Encyclopedia Britannica. https://www.britannica.com/technology/computer-simulation

[31] Macdonald, R. and Eng, P. (2003) Theory and Objectives of Air Dispersion Modelling. University of Waterloo, Waterloo, 1-27.

[32] Harting, C. (2010) Curt Harting. AC Transmission Line Losses. http://large.stanford.edu/courses/2010/ph240/harting1/

[33] Erickson, J. (2015) Minimum Spanning Trees. Algorithms, Etc. http://jeffe.cs.illinois.edu/teaching/algorithms/ 
[34] Shiffman, D. (2016) 9.9: Minimum Spanning Tree (Prim’s Algorithm). https://www.youtube.com/watch?v=BxabnKrOjT0

[35] Skiena, S.S. (2008) The Algorithm Design Manual. 2nd Edition, Springer, London. https://doi.org/10.1007/978-1-84800-070-4

[36] Ahuja, R.K., Magnanti, T.L. and Orlin, J.B. (1993) Network Flows: Theory, Algorithms, and Applications. Prentice Hall, Upper Saddle River.

[37] Fontenla, M. (2014) Optimal Trees in Weighted Graphs. https://cran.r-project.org/web/packages/optrees/optrees.pdf

[38] EPA (1995) User's Guide for the Industrial Source Complex (ISC3) Dispersion Models. U.S. Environmental Protection Agency, Durham, Vol. II, 1-128, Rep. No. EPA-454/B-95-003b.

[39] METI (2005) Ministry of Economy, Trade and Industry Low Rise Industrial Source Dispersion Model METI-LIS Model. Ministry of Economy, Trade and Industry of Japan, Tokyo, 1-56.

[40] Turner, D. (1970) Workbook of Atmospheric Dispersion Estimates. U.S. Environmental Protection Agency, 7th Printing January 1974 Office of Air Programs Publication No. AP-26, 1-92.

[41] Ransom, L. (2013) Fermat Point. https://lcransom.files.wordpress.com/2015/06/fermat-point.pdf 